\title{
ESTUDO DOS LIPÍDIOS EM JOVENS PORTADORES DE ESQUISTOSSOMOSE HEPATOESPLÊNICA SUBMETIDOS A TRATAMENTO CIRÚRGICO ${ }^{1}$
}

\author{
Schirley Nóbrega da Silva ${ }^{2}$ \\ Keyla Fontes de Oliveira ${ }^{3}$ \\ Carlos Teixeira Brandt ${ }^{4}$ \\ Vera Lúcia de Menezes Lima ${ }^{5}$
}

\begin{abstract}
Silva SN, Oliveira KF, Brandt CT, Lima VLM. Estudo dos lipídios em jovens portadores de esquistossomose hepatoesplênica submetidos a tratamento cirúrgico. Acta Cir Bras [serial online] 2002 Jul-Ago;17(4). Disponível em URL: http://www.scielo.br/acb.
\end{abstract}

RESUMO - Objetivo: Avaliar o metabolismo lipídico em uma população de jovens portadores de esquistossomose na forma hepatoesplênica associada a varizes sangrentas de esôfago. Métodos: Foram selecionados, aleatoriamente, 20 jovens com estas anormalidades, submetidos a esplenectomia, ligadura da veia gástrica esquerda e auto-implante de tecido esplênico no omento maior. Como controle foram selecionados 20 adolescentes saudáveis, com a mesma condição sócio-econômico ambiental do grupo estudo. Destes dois grupos, obtiveram-se plasma e eritrócitos de onde foram extraídos, separados e dosados os lipídios neutros, colesterol livre e esterificado, fosfolipídios e triglicerídios. Resultados: A concentração molar de colesterol total do grupo de pacientes foi discretamente reduzida quando comparada ao grupo de indivíduos controles. Resultados similares foram observados com as frações de colesterol esterificado e colesterol livre. Houve redução na concentração de triglicerídios plasmáticos mas não significativa. Os fosfolipídios individuais apresentarem concentração relativa similar aos do grupo controle, entretanto houve redução significativa $(\mathrm{p}<0,01)$ na fração fosfatidiletanolamina dos pacientes, cuja redução não alterou significatvamente os fosfolipídios totais plasmáticos. Na membrana eritrocitária, os níveis de colesterol total e fosfolipídio total, não sofreram alterações significativas. Conclusão: Os dados sugerem haver normalização nos níveis lipídicos no plasma e na membrana eritrocitária dos pacientes submetidos ao tratamento efetuado.

DESCRITORES - Esquistossomose mansônica hepatoesplênica. Lipídios. Colesterol. Fosfolipídios.

\section{INTRODUÇÃO}

O Schistosoma mansoni é bastante difundido no mundo. No Nordeste do país, o Estado de Pernambuco apresenta 82 dos seus 115 municípios, endêmicos para esquistossomose, observando-se expansão da endemia uma vez que em 1996 o número de municípios atingido era $77^{1,2}$. A forma hepato-esplênica é causa comum de hipertensão portal em adolescentes e adultos jovens na região ${ }^{3}$. Há indicação de esplenectomia na infância quando se associam a essa parasitose, varizes de esôfago e distúrbios do crescimento. Brandt, et al. ${ }^{4}$, vêm utilizando a esplenectomia associada ao auto-implante de tecido esplênico, em bolsa, no omento maior e ligadura da veia gástrica esquerda, há 11 anos. A esplenose decorrente desta técnica fez desaparecer a mortalidade por septicemia fulminante pós-esplenectomia (overwhelming post-splenectomy infection, OPSI), em crianças, possibilitando maior sobrevida e seguimento prolongado.

1. Trabalho realizado no Laboratório de Química e Metabolismo de Lipídios e Lipoproteínas do Departamento de Bioquímica do CCB/UFPE e no Serviço de Cirurgia Geral da Criança do Departamento de Cirurgia do HC - CCS/UFPE.

2. Mestre em Bioquímica, Departamento de Bioquímica do CCB/UFPE.

3. Profa. Adjunta Doutora de Neurologia e Puericultura da FCM/UPE.

4. Prof. Titular Doutor de Cirurgia Pediátrica do CCS/UFPE.

5. Profa. Adunta Doutora do Departamento de Bioquímica do CCB/UFPE. 
Os lipídios além de serem os maiores produtores da energia corpórea, participam na estrutura das membranas e na formação de hormônios esteróides, prostaglandinas, ácidos biliares, contribuindo na manutenção das funções vitais ${ }^{5}$. Os estudos de lipídios na esquistossomose hepatoesplênica reportam-se a pacientes submetidos a esplenectomia total e tempo de seguimento pós-cirúrgico curto, geralmente menor de seis meses ${ }^{6}$.

Está demonstrado em humanos e em estudos experimentais ${ }^{7}$, que há anormalidades do metabolismo lipídico na forma hepatoesplênica da esquistossomose detectadas em alterações nos níveis plasmáticos e na composição das membranas eritrocitárias. São encontradas: diminuição da concentração de colesterol total (CT); do colesterol esterificado (CE) e aumento do colesterol livre (CL); aumento da concentração da fosfatidil colina ou lecitina (PC) com diminuição da lisofosfatidil colina (LPC) e redução da fosfatidil etanolamina (PE); aumento da relação molar colesterol/fosfolipídios; diminuição dos níveis de triglicerídios (TG); redução da atividade da lecitil:colina acetiltransferase (LCAT); e diminuição da HDL. Essas modificações podem se dever à redução da atividade da LCAT, enzima catalisadora da esterificação do colesterol no processo de transporte reverso do colesterol ${ }^{8,9}$.

O objetivo deste estudo foi a avaliação do metabolismo lipídico em pacientes jovens esquistossomóticos submetidos a esplenectomia, ligadura da veia gástrica esquerda e esplenoses.

\section{MÉTODOS}

\section{Pacientes e procedimentos}

Foram coletadas amostras do sangue venoso de 20 pacientes tomados como controle, com 13 a 20 anos, saudáveis, procedentes escola pública de Recife$\mathrm{PE}$, com padrão sócio ambiental semelhante ao do grupo esquistossomótico e 20 pacientes, de 13 a 21 anos, em retorno para seguimento de esplenectomia por esquistossomose hepatoesplênica, realizada entre os 8 e 16 anos de idade. Com o objetivo de estudo do metabolismo lipídico nestes grupos de indivíduos, foram obtidos plasma e eritrócitos, realizada extração, separação em cromatografia fina, seguidos da dosagem química do colesterol livre e esterificado, dos fosfolipídios e a determinação dos triglicerídios, cujos métodos utilizados estão descritos na literatura ${ }^{10-13}$.

\section{Material químico}

Solventes orgânicos: acetona, ácido acético, benzeno, clorofórmio, éter etílico, isopropanol, hexano, metanol, tolueno todos de grau para análise (Merck S/ A). Padrões: colesterol livre, esfingomielina, fosfatidiletanolamina, lisofosfatidilcolina (Sigma Chemical Company) Produtos químicos analíticos: hidróxido de $\mathrm{Na}$, cloreto de $\mathrm{K}$, hidróxido de $\mathrm{K}$, sulfato de sódio, álcool isopropílico, cloreto férrico, ácido sulfúrico, molibdato de $\mathrm{Na}$, metabissulfito de $\mathrm{Na}$, ácido 1-amino2-naftolsulfônico (ANSA), ácido etilenodiaminotetracético (EDTA), cloreto de sódio, glicerol, carbonato de $\mathrm{Na}$, peróxido de $\mathrm{H}$, sílica gel $\mathrm{H}$ e sílica $\mathrm{G}$, (Merck do Brasil). Kit de ensaio enzimático colorimétrico para triglicerídios (Labtest Diagnóstica).

\section{Análise estatística}

Utilizou-se o teste $t$ de Student para amostras não pareadas. $\mathrm{p}<0,05$ rejeitou a hipótese de nulidade.

\section{RESULTADOS}

\section{Níveis dos lipídios plasmáticos}

Os níveis plasmáticos dos lipídios do grupo controle e dos pacientes estudados, bem como a concentração relativa do CE, estão demonstrados na Tabela 1 .

Tabela 1 - Níveis plasmáticos dos lipídios de grupo controle e de grupo de pacientes esquistossomóticos submetidos a esplenectomia, ligadura de veia gástrica esquerda e auto-implante esplênico.

\begin{tabular}{l|l|ll}
\hline Análise bioquímica & Grupo controle & \multicolumn{2}{|l}{ Grupo de pacientes } \\
\hline Colesterol total $(\mathrm{mM} / \mathrm{L})$ & $4,02 \pm 0,69$ & $4,01 \pm 0,84$ & $\mathrm{p}>0,05$ \\
\hline Colesterol livre $(\mathrm{mM} / \mathrm{L})$ & $1,35 \pm 0,30$ & $1,29 \pm 0,29$ & $\mathrm{p}>0,05$ \\
\hline Colesterol esterificado $(\mathrm{mM} / \mathrm{L})$ & $2,67 \pm 0,47$ & $2,64 \pm 0,56$ & $\mathrm{p}>0,05$ \\
\hline Colesterol esterificado $(\%$ do total) & 66,4 & 65,8 & \\
\hline Triglicerídios $(\mathrm{mM} / \mathrm{L})$ & $0,60 \pm 0,19$ & $0,58 \pm 0,18$ & $\mathrm{p}>0,05$ \\
\hline Fosfolipídios totais $(\mathrm{mM} / \mathrm{L})$ & $1,32 \pm 0,21$ & $1,34 \pm 0,18$ & $\mathrm{p}>0,05$ \\
\hline Fosfatidilcolina $(\% \mathrm{mM} / \mathrm{L})$ & 64,15 & 66,74 & \\
\hline Lisofosfatidilcolina $(\mathrm{mM} / \mathrm{L})$ & 16,31 & 16,4 & \\
\hline Esfingomielina $(\mathrm{mM} / \mathrm{L})$ & 12,09 & 10,86 & $\mathrm{p}<0,05$ \\
\hline Fosfatidiletanolamina $(\mathrm{mM} / \mathrm{L})$ & $7,42 \pm 1,32$ & $5,91 \pm 1,04$ & \\
\hline
\end{tabular}


Tabela 2 - Concentração molar do colesterol total e fosfolipídios totais da membrana eritrocitária de grupo controle e de pacientes esquistossomóticos submetidos a esplenectomia, ligadura de veia gástrica esquerda e auto-implante esplênico.

\begin{tabular}{l|l|ll}
\hline Análise bioquímica $(\mathrm{mM} / \mathrm{l})$ & Grupo controle & \multicolumn{3}{|c}{ Grupo de pacientes } & \\
\hline Colesterol total & $3,17 \pm 0,67$ & $3,09 \pm 0,78$ & $\mathrm{p}>0,05$ \\
\hline Fosfolipídios totais & $3,71 \pm 0,42$ & $3,73 \pm 0,52$ & $\mathrm{p}>0,05$ \\
\hline
\end{tabular}

\section{DISCUSSÃO}

A concentração molar de CT no plasma do grupo de pacientes e do grupo controle mostrou similaridade nesta pesquisa. Os resultados também foram similares para as concentrações molares das frações CE e CL.
Comparando com dados da literatura (Tabela 3), de pacientes submetidos a esplenectomia total, verificamse resultados diferentes dos encontrados no presente estudo, ocorrendo evidente redução nas concentrações molares de CT, CL, CE, TG, FLT e das classes fosfolipídicas.

Tabela 3 - Níveis plasmáticos dos lipídios de grupo controle e pacientes esquistossomóticos submetidos a esplenectomia com técnicas clássicas.

\begin{tabular}{l|l|c|c|c}
\hline & \multicolumn{2}{c|}{ Carvalho, 1976 } & \multicolumn{2}{c}{ Gillett \& Coelho, 1979 } \\
\cline { 2 - 5 } & $\begin{array}{c}\text { Grupo } \\
\text { controle }\end{array}$ & $\begin{array}{c}\text { Grupo } \\
\text { de pacientes }\end{array}$ & $\begin{array}{c}\text { Grupo } \\
\text { controle }\end{array}$ & $\begin{array}{c}\text { Grupo } \\
\text { de pacientes }\end{array}$ \\
\hline Colesterol total (mM/l) & $4,61 \pm 1,11$ & 3,65 & $4,31 \pm 0,72$ & $3,03 \pm 0,54$ \\
Colesterol livre & $1,32 \pm 0,32$ & 0,81 & - & - \\
Colesterol esterificado (mM/l) & $3,28 \pm 0,77$ & 2,84 & - & - \\
Colesterol esterificado(\% do total) & 71,3 & 67,8 & 70,6 & 68,2 \\
Triglicerídios (mM/l) & - & - & $1,49 \pm 0,34$ & $0,73 \pm 0,19$ \\
Fosfolipídios totais (mM/l) & $2,69 \pm 0,54$ & 2,15 & $2,38 \pm 0,33$ & $2,50 \pm 0,35$ \\
\hline
\end{tabular}

A variação da concentração relativa de $\mathrm{CE}$ em publicações anteriores, foi muito diminuída, de $2,4 \%$ a $3,5 \%$, enquanto no atual trabalho foi de $0,6 \%$. A concentração de TG no plasma de grupo de pacientes esquistossomóticos comparada à do controle, no atual estudo, mostrou diferença de $4 \%$ entre controles e os pacientes, variando pouco ao ser confrontada com as análises de Gillett e Coelho ${ }^{6}$ cujas diferenças são elevadas, na ordem de $50 \%$.

Estudos experimentais ${ }^{7}$, abstraindo fatores de confusão, confirmam que há alterações do metabolismo lipídico na esquistossomose mansônica, caracterizadas redução no CE e CT. Chamou a atenção, portanto, o encontro da similaridade dos níveis lipídicos dos grupos neste estudo uma vez que, em pesquisa anterior no mesmo laboratório com os mesmos pacientes esquistossomóticos, esplenectomizados, foi encontrada atividade da lecitina:colesterol aciltransferase significativamente diminuída. Existe a possibilidade de ter havido modificação metabólica após o tratamento. Os resultados similares obtidos talvez decorressem da esterificação do colesterol por outra enzima que não a LCAT como por exemplo a colesterol:aciltransferase $\mathrm{e}^{9,14}$.
As concentrações relativas dos fosfolipídios plasmáticos SPH, PC, LPC, PE no plasma de pacientes esquistossomóticos esplenectomizados, em relação aos indivíduos controles saudáveis demonstram que no plasma do grupo de pacientes, os níveis de PC foram aumentados e os de LPC e PE foram reduzidos, em comparação com o grupo controle, entretanto essa variação na concentração tenha sido apenas significante para PE.

Owen \& Gillett ${ }^{15}$, encontraram evidente redução nos LPC e aumento de PC plasmáticos na esquistossomose mansônica hepatoesplênica. Apesar dessa alteração dos fosfolipídios, não foi observada diferença significativa na concentração molar dos FLT plasmáticos dos pacientes, comparada com os controles. A relação molar CT/CLT foi levemente reduzida nos pacientes comparada com os controles, de modo semelhante aos resultados da concentração dos outros lipídios plasmáticos. Estes resultados poderiam estar ligados às modificações do metabolismo lipídico da esquistossomose hepatoesplênica.

$\mathrm{Na}$ análise da composição dos lipídios eritrocitários, os níveis de CT e de FLT na membrana eritrocitá- 
ria de pacientes esquistossomóticos submetidos à esplenectomia também não mostraram alterações significativas nas concentrações molares de CT e de FLT, quando comparados aos controles. Membrana celular, lipídios plasmáticos e lipoproteínas transportadoras estão associados em termos funcionais e distúrbio do seu metabolismo pode ser deletério para a função celular ${ }^{5}$.

A comparação do presente trabalho com estudos anteriores realizados, sugere uma normalização dos lipídios eritrocitários em pacientes esquistossomóticos que foram submetidos à esplenectomia associada a autoimplante esplênico e ligadura de veia gástrica esquerda.

\section{CONCLUSÃO}

Os níveis de lipídio no plasma e eritrócitos dos pacientes esquistossomóticos jovens, submetidos a esplenectomia, ligadura da veia gástrica esquerda e autoimplante de fragmentos esplênicos no omento maior foram similares aos do grupo controle, entretanto, apresentou menor concentração de fosfatidiletanolamina

\section{REFERÊNCIAS}

1. Secretaria do Estado de Pernambuco/ Funasa. Boletim epidemiológico. 2001; $1: 1$.

2. Barbosa CS. Esquistossomose em Pernambuco: determinantes bioecológicos e sócio-culturais em comunidade agrícola [Tese - Doutorado] Escola Nacional de Saúde Pública; 1996.

3. Pitella JEH, Lana-Peixoto MA. Brain involvement in hepatesplenic schistosomiasis mansoni. Brain 1981; 104:621-32.
4. Brandt CT, Maciel DT, Caneca AOF. Esplenose associada ao tratamento cirúrgico da hipertensão porta esquistossomótica na criança: avaliação de dez anos. An Fac Med Univ Fed Pernamb 1999; 44:15-20.

5. Devlin TM. Textbook of biochemistry with clinical correlations. New York: Wiley-Liss; 1997.

6. Gillett MPT, Coêlho LCBB. The effect of splenectomy on plasma phosphatidylcholine-cholesterol acyltransferase activity and blood lipids in human schistosomiasis mansoni. Bioch Soc Trans 1979; 7:988-90.

7. Lima LMV, Sena LM, Stewart B, Stewart B, Owen JS, Dolphin JP. An evaluation of marmoset Callithrix jacchus (sagüi) as an experimental model for the dyslipoproteinemia of human Schistosomiasis mansoni. Bioch Bioph Acta. 1998; 1393:235-43.

8. Gillett MPT, Owen JS, Coutinho A. Plasma free and sterified cholesterol in schistosomiasis mansoni. Lancet 1976:971.

9. Lima LMV, Coelho LCBB, Owen JS, Kennedy JF, Dolphin PJ. Lecithin:cholesterol acyltransferase (LCAT): a brief review as a glycoprotein. Carbohydrate Polymers. 2001. (In Press) (RP 525).

10. Folch J, Less M, Stanley GHS. A simple method for the isolation and purification of total lipids from animal tissues. J Bras Cir 1957; 226:497-509.

11. Bartlett GR. Phosphorus assay chromatography. J Biol Chem. $1959 ; 234: 466-8$.

12. Nelson GJ. Composition of neutral lipids from erythrocytes of common mammals. J Lip Res 1967; 8:374-9.

13. Leffler HH. Method for cholesterol and cholesterol esters in serum .In: Sunderman, F W, Sunderman Jr. FW. Lipids and steroids hormones in clinical medicine. Philadelphia: Lippincott, 1960.

14. Lima LMV, Harry DS, Mcintyre N, Owen JS, Chaves MEC. Characterization and potential use of rabbit polyclonal antibodies against human lecithin:cholesterol acyltransferase. Bras J Med Biol Res 1996; 29:957-68.

15. Owen JS, Gillett MPT. Lecithin:cholesterol acyltransferase deficiency associated with hepatic Schistosomiasis mansoni. Scan J Clin Lab Inv 1978; 38:194-8.

Silva SN, Oliveira KF, Brandt CT, Lima VLM. A lipid study of schistosomotic young people underwent surgical treatment. Acta Cir Bras [serial online] 2002 Jul-Aug;17(4). Available from URL: http://www.scielo.br/acb.

ABSTRACT - Objective: To evaluate the lipid metabolism in a population of young people, with the hepatesplenic form of schistosomiasis mansoni, associated with bleeding esophageal varices. Methods: 20 young patients were selected, at random, and compared to a control group of 20 healthy young people with the same social, economical and environmental conditions. The patients had undergone splenectomy, ligature of the left gastric vein and auto implantation of spleen tissue into the major omentum. From these two groups were obtained plasma and erythrocytes, and it were extracted, separated and determinated the neutral lipids, free cholesterol and ester, phospholipids and triglicerides levels. Results: The results appointed that the total molar concentration of total, cholesterol was similar to the group of the patients, which was similar to the control group. Similar results were observed with the fractions of ester and free cholesterol. There was a reduction on the concentration of plasmatic triglicerides, but without significance. The individual's phospholipids presented relative concentration, similar to the control group, but there was significant reduction $(\mathrm{p}<0,01)$ in the patient's phosphatidilethanolamine fraction, however, there was no significantly reduction of molar concentration of total plasmatic phospholipids, compared to the controls. In the erythrocyte membrane, the total cholesterol and. total phospholipids levels do not suffered significant alterations. Conclusion: The obtained data indicated a similarity of the lipids levels in the plasma and in the erythrocyte membrane of the patients submitted to the surgical treatment.

KEY WORDS - Hepatosplenic schistosomiasis mansoni. Lipids. Cholesterol. Phospholipids.

Endereço para correspondência:

Carlos Teixeira Brandt

Universidade Federal Pernambuco - Centro Ciências Saúde

Av. Moraes Rêgo, s/n HC - Bloco A

50670-420 Recife - PE - Tel/Fax: (81)3271-8519
Conflito de interesse: nenhum Fonte de financiamento: nenhuma

Data do recebimento: $22 / 03 / 2002$

Data da revisão: $12 / 04 / 2002$

Data da aprovação: 23/05/2002 